\title{
A INTERDISCIPLINARIDADE COMO CONSTRUÇÃO DO CONHECIMENTO EM SAÚDE E ENFERMAGEM ${ }^{1}$ \\ INTERDISCIPLINARITY AS KNOWLEDGE CONSTRUCTION IN HEALTH CARE AND NURSING LA INTERDISCIPLINARIEDAD COMO LA CONSTRUCCIÓN DEL CONOCIMIENTO EN LA SALUD Y EN ENFERMERÍA
}

\author{
BetinaHömer SchlindrweinMeirelles', Alacoque LorenziniErdmann ${ }^{3}$
}

\begin{abstract}
${ }^{1}$ Texto elaborado a partir da tese de doutorado "Viver Saudável em Tempos de Aids: a complexidade e a interdisciplinaridade no contexto da prevenção da infecção pelo HIV”, defendida no Programa de Pós-Graduação em Enfermagem da Universidade Federal de Santa Catarina (UFSC) em 2003.

${ }^{2}$ Enfermeira. Doutora em Enfermagem. Professora do Curso de Graduação em Enfermagem da UFSC.

${ }^{3}$ Enfermeira. Doutora em Filosofia da Enfermagem. Professora Titular do Departamento de Enfermagem da UFSC. Pesquisadora e Representante de Área CNPq. Orientadora da Tese.
\end{abstract}

PALAVRAS-CHAVE: Ação intersetorial. Promoção da saúde. Enfermagem. Conhecimento.

KEYWORDS: Intersectorial action. Health promotion. Nursing. Knowledge.

PALABRAS CLAVE: Acción intersectorial. Promoción de la salud. Enfermería. Conocimiento.
RESUMO: Este artigo resulta de uma síntese sobre a interdisciplinaridade na construção do conhecimento e práticas em saúde/enfermagem, considerando as múltiplas dimensões que envolvem o processo saúdedoença e a promoção da saúde das comunidades. O objetivo é propiciar reflexão e melhor compreensão da realidade dinâmica e complexa, que impõe que se estabeleça múltiplas interconexões para que as ações se efetivem na promoção da saúde. O pensamento em saúde ainda é fragmentado, levando a ações de prevenção e controle de doenças pontuais e enfoque mutilado da realidade vivida pelos sujeitos. O estabelecimento das inter-relações e integrações disciplinares propiciará uma consciência capaz de enfrentar as complexidades e a integralidade do processo de viver saudável. A partir dessa compreensão, sugere-se a construção de um conhecimento contextualizado em saúde/enfermagem, que responda às necessidades dos sujeitos e facilite a criação de parcerias entre múltiplos atores/sistemas sociais na abordagem por melhores condições de saúde e vida.

ABSTRACT: This article is the result of a synthesis about interdisciplinarity in constructing knowledge and practices in health care and Nursing, considering the multiple dimensions which involve the health and illness processes and health promotion in communities. The objective of this study is to propitiate better comprehension about the complexity and dynamism of the reality that demands professionals to establish interrelationships among their actions, aiming for effective health promotion. The concepts of health are still fragmented, resulting in reducing professionals' actions toward prevention to controlling illness without considering the individuals' daily life context. Whereas, the professional that establishes the interrelationships between disciplines will be able to face the complexities and wholeness of healthy living process. From this comprehension, the author suggests knowledge construction based on a health care/Nursing context that meets individuals' necessities and facilitates the development of a net partnership between social actors, seeking better health and life conditions for individuals.

RESUMEN: Este artículo resulta de una síntesis sobre la interdisciplinariedad en la construcción del conocimiento y prácticas en salud/enfermería, considerando las múltiples dimensiones que envuelven el proceso salud-enfermedad y la promoción de la salud de las comunidades. El objetivo es propiciar la reflexión y mejorar la comprensión de la realidad dinámica y compleja, que impone que se establezcan múltiples interconexiones para hacer efectivo las acciones en la promoción de la salud. El pensamiento en la salud, todavía, continua fragmentado, llevando las a acciones de prevención y el control de enfermedades puntuales y a um enfoque mutilado de la realidad vivida por las personas. El establecimiento de las interrelaciones e integraciones disciplinares propiciará una conciencia capaz de enfrentar las complejidades y la integridad del proceso de vivir saludable. A partir de esta comprensión, se sugiere la construcción de un conocimiento contextualizado en salud-enfermería, que responda a las necesidades de las personas y facilite la creación de parcerías entre múltiples actores/sistemas sociales en el abordaje por mejores condiciones de salud y de vida.
Endereço:

Betina Hörner Schlindwein Meirelles

Av. Gov. Irineu Bornhausen, 3188, Apto 801

88025-200 - Florianópolis, SC.

E-mail: betinahsm@ig.com.br
Artigo original: Reflexão

Recebido em: 15 de fevereiro de 2005

Aprovação final: 13 de abril de 2005 


\section{INTRODUÇÃO}

A dinâmica e as transformações que vêm ocorrendo na sociedade refletem de maneira significativa no campo da saúde, trazendo novos desafios aos pesquisadores e profissionais da saúde tanto nos campos epistemológicos como metodológicos. O setor saúde é chamado a responder a uma pluralidade de necessidades e especificidades, às mudanças demográficas, às condições sociais, às mudanças epidemiológicas, centrando-se no ser humano, individual ou coletivo.

A saúde coletiva e pública, como proposta centrada na promoção da qualidade de saúde e vida dos homens, tem nas práticas interdisciplinares um espaço privilegiado para repensar teorias, inovar seus conhecimentos e as formas de pensar a saúde, a doença e a prestação de serviços, e se concretizar como um movimento que aglutine o saber e os sujeitos desse saber. Envolve pensar a respeito da realidade. Necessita do encontro, de troca entre os diversos setores da sociedade, entre investigadores na busca das respostas às questões em aberto.

Convivemos com a necessidade de diferentes abordagens para entender a realidade e enfrentar os problemas que se apresentam, buscando múltiplas teorias para explicá-los. Assim, a saúde torna-se um processo dinâmico e complexo, cuja compreensão aponta a reflexões interdisciplinares para uma nova prática em saúde e Enfermagem, como nos propomos a discutir neste texto.

\section{UMA BREVE REFLEXÃO A RESPEITO DO CONCEITO DE INTERDISCIPLINA- IDADE EM SAÚDE E ENFERMAGEM}

A abordagem interdisciplinar nos leva como ponto de partida, a uma discussão a respeito do termo interdisciplinaridade, tão comumente usado em nosso meio. Podemos até dizer que o termo está na "moda" e é facilmente confundido com o trabalho em equipe ou em grupo, tanto na pesquisa como na resolução de um problema prático.

No caso da saúde, coloca-se que "a busca de ações integradas na prestação de serviços, ou na associação de docência e serviço, ou a questão da interface entre o biológico e o social passa pelo campo genericamente denominado de relações interdisciplinares", 198 como resposta à compartimentalização que procura responder aos problemas de saúde, que geralmente não são disciplinares. Assim, uma abordagem interdisciplinar, com o olhar da complexidade em saú- de, se caracteriza pela necessidade de aporte de outros conhecimentos, principalmente das Ciências Humanas e Sociais à saúde, numa superação do enfoque muitas vezes biomédico, curativista e fragmentado que se tem adotado na abordagem da problemática.

Porém, a questão não é a simplificação de interligar os conhecimentos, mas deve-se levar em consideração a intervenção efetiva no campo da realidade social. "O problema assume maior complexidade na medida em que a disciplinaridade e a interdisciplinaridade necessitam ser vistas em seus condicionantes histórico-sociais no contexto de uma sociedade em que a especialização e a proliferação e fragmentação do conhecimento passam a fazer parte de uma sociedade competitiva e corporativista". 1:98

A nova visão de saúde coletiva e pública, em construção na América Latina, traz a necessidade de uma sistematização do conceito de saúde, situando suas potencialidades de constituição de um conhecimento interdisciplinar. Enfim, no sentido de que este movimento ideológico se articule a novos paradigmas científicos capazes de abordar o objeto complexo saúde-doença respeitando sua historicidade e integralidade, reconhecendo as várias facetas dos fenômenos da vida cotidiana envolvidos neste processo.

Neste sentido, consideramos importante a discussão a respeito destes novos paradigmas, como também a pertinência do debate entre profissionais e instituições de saúde em busca desta nova prática sanitária, tal como também propõe a Organização Mundial da Saúde através de suas Conferências para a promoção da saúde dos povos.

Novos paradigmas trazem novas formas de pensamento e de visão de mundo. O pensamento simplificador vigente na saúde desenvolveu-se, no quadro soberano dos três axiomas da lógica identitária clássica. ${ }^{2}$ Foi justamente isso que produziu um pensamento redutor ocultando a solidariedade, interretroações, sistemas, organizações, emergências, totalidades e suscitou conceitos unidimensionais, fragmentados e mutilados do real. Foi o que levou a ciência clássica à visão determinista/atomista de um universo-máquina constituído de bases isoláveis.

A idéia de interdisciplinaridade já vem desde os filósofos gregos com a possibilidade de formar um homem integral, voltando à discussão nos tempos atuais, na década de 60, com os trabalhos de Gusdorf, Piaget, Bastide, Jantsch, dentre outros, com a possibilidade de unir os conhecimentos que vão se fragmentando nos espaços especializados. Porém, somente na 
década de 70, principalmente com as conclusões de um encontro sobre interdisciplinaridade organizado pela Organização da Comunidade Européia para o Desenvolvimento Econômico (OCDE), é que recebe seu maior impulso. ${ }^{3}$

Na década de 90 , a interdisciplinaridade toma outra forma diante do mundo de informação e de crises que vivemos. Passa a ser vista de uma forma mais complexa, na busca de uma nova epistemologia. Vivemos a hiperespecialização em todas as áreas do conhecimento, os problemas fundamentais e os problemas globais são despejados das ciências disciplinares. As mentes formadas pelas disciplinas perdem suas aptidões naturais tanto para contextualizar os saberes, tanto como para integrá-los em seus conjuntos naturais. ${ }^{2} \mathrm{O}$ enfraquecimento da percepção do global conduz ao enfraquecimento da responsabilidade (cada um tende a responsabilizar-se somente pela sua tarefa especializada) e da solidariedade. A divisão das disciplinas impossibilita entender o que está tecido junto, ou o complexo, o que precisa ser mudado para que sejamos capazes de construir concepções e modelos mais aproximados da realidade.

Aponta-se que a justificativa de um projeto de pesquisa interdisciplinar, que ultrapasse os quadros das diferentes disciplinas científicas, deve ser procurada "na complexidade dos problemas aos quais somos hoje em dia confrontados, para chegar a um conhecimento humano, se não em sua integridade, pelo menos numa perspectiva de convergência de nossos conhecimentos parcelares" 3.62 Pois, de certa forma, os especialistas decompõem o homem em busca de um conhecimento positivo, um saber verificável, através de métodos científicos determinados.

É enfatizado ainda, que se necessita de uma nova forma de conhecimento do real e que esta consciência coletiva seria saturada de complexidade, de complexus, ou seja, de agires e fazeres que rejuntariam tudo aquilo que a disjunção cartesiana fez no plano físico, metafísico e metapolítico. Qualquer sistema vivo passaria, então, a ser entendido como um sistema incompleto, indeterminado, irreversível, sempre marcado pela autoorganização que combina, descombina e recombina a ordem, a desordem e a desorganização. ${ }^{2}$

Ao discutirmos os conceitos de interdisciplinaridade, é comum a visão de uma resposta à fragmentação do saber para a construção de um saber que dê conta da totalidade da realidade, o saber unitário. Esta unidade está presente na construção de um sistema conceitual resultante da integração dos sistemas disciplinares, que pode conduzir à introdução de uma nova noção, a transdisciplinaridade.

Ora, aqui temos um ponto bastante significativo para a discussão. O que é esta unidade? Temos que estar atentos, pois a unidade é metafísica, é redutora, leva da mesma forma ao fechamento em si mesmo ou "emmesmesamento". A realidade é dinâmica e não se fecha em si, não sendo redutível à mensuração. $\mathrm{O}$ real está em constante movimento, em constante relação entre o geral e o específico, o universal e o particular, entre o uno e o diverso.

Apesar de considerar a unidade como não acabada, por conseguinte aceitando a sua dinamicidade, ${ }^{3}$ concordamos que existe a necessidade de delimitarmos um objeto para investigação, mas sem verdades prévias, considerando as múltiplas determinações que o constitui e a dinamicidade e complexidade da realidade em que se insere.

Também não existe uma metodologia interdisciplinar, pois não podemos ter essa pretensão de prever o imprevisível diante da dinamicidade da realidade. Enfatiza-se que, ao contrário de Descartes que partia de um princípio simples de verdade e por isso propunha um discurso do método em poucas páginas, Morin faz um discurso muito longo "à procura de um método que não se revela por nenhuma evidência inicial, mas que deve elaborar-se com esforço e risco. A missão desse método não é fornecer fórmulas programáticas de um pensamento 'são', mas convidar a pensar a si mesmo na complexidade". ${ }^{4.55}$

As construções científicas não podem ser pensadas como tendo a ver com a verdade, segundo o conceito tradicional, metafísico. "Não são cópias do mundo dado. São reorganizações do mundo congruentes com o sujeito produtor". .56

Não há simplesmente a unidade, mas há unidade na diversidade, universal e particular. Assim, quando falamos em unidade temos que estar atentos ao sentido que está sendo atribuído. Não se pode conceber unidade sem multiplicidade; só há unidade quando há um referente, que no caso é a multiplicidade. A unidade é dialética, pois é multiplicidade em movimento. E a dialética única negaria sua própria identidade, ou seja, a unidade dos contrários. A dialética, mais que outras metodologias, sabe apontar para o caráter contraditório e ambíguo da realidade e de si mesma. "Como todas é lógica, ou seja, também representa a intenção de catar padrões na complexidade, mas dentro da perspectiva essencialmente dinâmica". ${ }^{6}$ É múltipla como todos os produtos também culturais, é essencialmente aberta e evolui sem direção determinada. 
Devemos conceber uma unidade que garanta e favoreça a diversidade, uma diversidade inscrita na unidade. A unidade complexa: unidade na diversidade, diversidade na unidade, unidade produtora de diversidade, diversidade produtora de unidade; é a unidade de um complexo gerador "[...] que gera diversidade ilimitada".7:66

A discussão sobre a interdisciplinaridade entre as ciências articulando os saberes de outras áreas, demonstra que "pela lógica da produção/construção do saber e por sua autonomia, as ciências não são fragmentos de um saber unitário e absoluto. Sua gênese não provém daí" .5:63 A existência de um fragmento pressupõe a existência de um todo que se perdeu no tempo, como se as ciências tivessem surgido de maneira linear e dependente de saberes anteriores - assim a autonomia e a produção científica são vistas como fragmentação. Neste sentido, afirma que o que se perdeu no decorrer do tempo foi aquela "unidade natural" do homem primitivo e sem história imerso na natureza e dela inteiramente dependente.

Mas, afinal, o que pretendemos com a interdisciplinaridade? $\mathrm{O}$ abandono da concepção fragmentária por outra unitária do saber e do conhecimento? Uma nova verdade científica?

Consideramos oportuno discutir a respeito, começando com o que definimos como verdade. A verdade que acreditamos não se trata de uma verdade definitivamente adquirida, mas de uma reflexão que cada um de nós deve realizar a respeito das questões que se colocam em nossa sociedade, com pontos de vista diversos. Considera-se a verdade não como algo que se impõe como dogma, mas sim, daquela que é alcançada através do diálogo e da polêmica, pois tal verdade traz em si a força da dialética. Diante da diversidade da realidade vivida, cabe à interdisciplinaridade possibilitar o conhecimento claro da interdependência das verdades.

A retirada da verdade e da certeza dá lugar ao imprevisível, ao incerto, deixando as pessoas sem saber o que pensar. Faz-se necessário resgatar alguma verdade sem recair num mundo verdadeiro. Compreendemos que a realidade dinâmica e complexa nos coloca que a verdade é flexível a esta dinamicidade do real, na expectativa de que ordens menos rígidas nos possibilitem conviver com as incertezas desta realidade. Assim, a verdade se constrói por aproximações sucessivas, abertas, que são constantemente questionadas para poder apreender a totalidade desta realidade.

Mas, retomando nossa discussão anterior, o que seria então esta unidade que buscamos? Como vimos, não é a verdade dogmática. O que pretendemos com a interdisciplinaridade é a busca de integração, de instaurar formas de totalidade em um campo de saber múltiplo, pluralista, heterogêneo; reconhecendo a complexidade dos fenômenos, dialeticamente, com olhares diferenciados, resgatando uma unidade que perdemos no decorrer da história.

Esta totalidade só é apreensível através das partes e das relações entre elas. A categoria da totalidade justifica-se "enquanto o homem não busca apenas uma compreensão particular do real, mas pretende uma visão que seja capaz de conectar dialeticamente um processo particular com outros processos e, enfim, coordená-lo com uma síntese explicativa cada vez mais ampla". 8:16 Implica uma complexidade em que cada fenômeno só pode vir a ser compreendido como um momento definido em relação a si e em relação aos outros fenômenos.

A totalidade não é um todo já feito, determinado e determinante das partes, não é uma harmonia simples, pois não existe uma totalidade acabada, mas um processo de totalização a partir das relações de produção e de suas contradições. Uma compreensão dialética da totalidade exige a relação entre as partes e o todo e as partes entre si. O todo, na verdade, só se cria a si mesmo na dialética das partes, só pode existir concretamente nas partes e é na relatividade das partes que o todo se estrutura e caminha. ${ }^{8}$

Assim, a totalidade é aberta, ligada ao movimento do real e em constante processo no seu desenvolver. Existem contradições no seio da totalidade que levam ao reconhecimento do real como histórico. A realidade está em movimento com suas contradições, o que a conduz à superação de si mesma. A totalidade concreta "não é algo que tenha uma existência em si. Ela é o processo de criação de sua estrutura porque é vista como uma produção social do homem". 8:37 O homem, como sujeito histórico-social, pela sua práxis objetiva produz a realidade e também por ela é produzido.

A totalidade "não é totalidade lisa, com partes tranqüilamente justapostas, estática, mas incompleta, aproximada, imprecisa: forma um todo porque existe dinâmica comum, mas mostra rachaduras constantes, por onde sempre pode entrar a antidinâmica da mudança. Não possui apenas a dinâmica circular, que é sempre a mesma e lhe permitiria recuperar-se eternamente. Ao contrário, a dinâmica é feita de dinâmicas contrárias, feitas de convergências e divergências" "6:108

Esta apreensão da totalidade nos exige um pen- 
samento complexo, capaz de conceber o que nos une, contextualizando o pensamento no sentido de que todo acontecimento, informação ou conhecimento seja considerado na relação da inseparabilidade com seu meio ambiente, seja cultural, social, econômico, político ou natural. "Trata-se de procurar sempre as relações e inter-retroações entre cada fenômeno e seu contexto, as relações de reciprocidade todo/partes; como uma modificação local repercute sobre o todo e como uma modificação do todo repercute sobre as partes. Tratase, ao mesmo tempo, de reconhecer a unidade dentro da diversidade, o diverso dentro da unidade; de reconhecer, por exemplo, a unidade humana em meio às diversidades individuais e culturais, as diversidades individuais e culturais em meio à unidade humana". ${ }^{9.25}$

Concluímos então que, quando pensamos em unidade na interdisciplinaridade, estamos adotando esta visão de totalidade, considerando o tempo, o espaço e o contexto (social, ético, político, econômico e outros) que constituem o real, num movimento dialético, complexo, considerando as suas múltiplas determinações. Estamos abandonando o pensamento que separa o que estáligado, que unifica o que é múltiplo, que simplifica o que é complexo, percebendo as interações e ligações entre os fenômenos e, considerando a irredutibilidade e complexidade do ser e viver humano.

Ao considerarmos estas definições, admitimos a visão de que a realidade é complexa e que esta complexidade só pode ser abordada numa visão interdisciplinar. O enfoque particular do real e como um sistema específico de relações do ser humano traz uma visão parcial da realidade, sem inter-relação do todo com as partes e das partes com o todo, como se o mundo fosse estático e o viver previsível.

Ao abordarmos este aspecto, torna-se relevante discutirmos a construção do conhecimento diante desta incerteza e imprevisibilidade do real, que nos mostra que saberes diversos são necessários para conceber este conhecimento. Não se trata de uma integração dos conhecimentos de forma sintética e harmoniosa. É uma tarefa difícil.

O problema da complexidade nos coloca "da dificuldade de permanecermos no interior de conceitos claros, distintos, fáceis, para concebermos a ciência, para concebermos o conhecimento, para concebermos o mundo em que estamos, para nos concebermos a nós na relação com este mundo, para concebermos a nós na nossa relação com os outros e para nos concebermos a nós na nossa relação com nós mesmos que é, afinal, a mais difícil de todas". 2.35

O problema não está em que cada um perca a sua competência, mas em compreender de que modo estão estruturados outros tipos de pensamento diferentes do nosso. "Está em que a desenvolva o suficiente para a articular com outras competências que, ligadas em cadeia, formariam o anel completo e dinâmico, o anel do conhecimento do conhecimento", ${ }^{2: 33}$ pois há necessidade de saberes diversos para que se conceba o conhecimento.

Pensamos que é necessário ultrapassar, relativizar e englobar num método de pensamento complexo, dialógico. A dialógica que propomos constitui não uma nova lógica, mas um modo de utilizar a lógica em virtude de um paradigma da complexidade. Cada operação fragmentária do pensamento dialógico obedece à lógica clássica, mas não o seu movimento em conjunto.

Cada uma das contradições que surgem na caminhada do conhecimento deve ser encarada na sua singularidade e problemática própria. É necessário “agir com". A contradição incita o pensamento complexo; nos servimos dela para reativar e complexificar o pensamento. É necessário um pensamento que saiba tratar, interrogar, eliminar e salvaguardar as contradições. É a tarefa do pensamento complexo.

Necessitamos de "uma cabeça bem-feita", que significa uma aptidão geral para colocar e tratar os problemas, bem como princípios organizadores que permitam ligar os saberes e lhes dar sentido, evitando a acumulação estéril do conhecimento. A organização do conhecimento comporta operações de ligação (conjunção, inclusão e implicação) e de separação (diferenciação, oposição, seleção e exclusão). ${ }^{9} \mathrm{O}$ processo é circular, comportando ao mesmo tempo separação e ligação, como análise e síntese. Morin ressalta que em nossa civilização ligação e síntese continuam subdesenvolvidas. A forma de organização do pensamento é que gera as fronteiras entre as disciplinas, por isso o problema é transformar estes princípios.

O desenvolvimento da aptidão para contextualizar e globalizar os saberes torna-se imperativo. O "conhecimento torna-se pertinente quando é capaz de situar toda a informação em seu contexto, e, se possível, no conjunto global ao qual se insere". ${ }^{418} \mathrm{Como}$ já citamos anteriormente, trata-se de reconhecer a unidade dentro do diverso, o diverso dentro da unidade.

Neste sentido, podemos considerar a complexidade como forma de pensamento, como um exercício cognitivo. Um pensamento que contextualiza, que adota visões complementares, num processo dinâmico de construção do conhecimento, produto da dialógica entre o certo e o incerto, entre a ordem e a 
desordem, entre o simples e o complexo presentes em nossa sociedade.

Ao dirigirmos a nossa discussão à saúde, salienta-se que no setor saúde temos geralmente uma visão disciplinar, corporativa, unidimensional, numa lógica linear, mecanicista e redutora, que de certa forma não pode explicar a complexidade do fenômeno saúde/ doença e da realidade. Assim, muitas vezes assume-se teorias que buscam explicar as ocorrências e os riscos de maneira unicausal, de maneira linear causa/efeito. É preciso aprender a ultrapassar a causalidade linear. "Compreender a causalidade mútua inter-relacionada, a causalidade circular (retroativa, recursiva), as incertezas da causalidade (porque as mesmas causas não produzem sempre os mesmos efeitos, quando os sistemas que elas afetam têm reações diferentes, e porque causas diferentes podem provocar os mesmos efeitos)". 9:77

Os indivíduos e as sociedades não podem produzir conseqüências senão através de causas, e como estas não ocorrem na mesma escala dos seus efeitos, não é possível partir do pressuposto de que o controle das causas acarreta o controle das conseqüências. Pelo contrário, a falta de controle sobre as conseqüências significa que as ações empreendidas como causas têm, não apenas as causas intencionais (lineares) da ação, mas uma multiplicidade imprevisível (potencialmente infinita) de conseqüências. ${ }^{10} \mathrm{O}$ controle das causas sendo absoluto, é absolutamente precário.

Este pensamento comum em saúde, leva a práticas voltadas a ações de prevenção e controle de doenças pontuais e com enfoque mutilado da realidade vivida pelos sujeitos. Desta forma, chegamos à discrepância entre a capacidade de ação (controle das causas) e a capacidade de previsão (controle das conseqüências), o que nos convida a um novo conhecimento mais próximo do real. Ao estabelecermos as inter-relações e os fenômenos multidimensionais, contextua-lizando o conhecimento, teremos uma consciência capaz de enfrentar as complexidades, como em nossas práticas, o processo de viver saudável na sua integralidade.

Hoje adotamos o conceito de vulnerabilidade e determinação social no processo saúde/doença, considerando uma multiplicidade de acontecimentos e de fenômenos, de riscos e de incertezas, no qual as estratégias cognitivas visam de modo complementar (e antagônico) simplificar e a complexificar o conhecimento, religando os saberes. ${ }^{2}$

Nossos acontecimentos da vida cotidiana devem ser contextualizados e pensados num processo de simplificação e de complexificação, considerando o provável e o improvável, o histórico, o certo e o incerto, o singular e o diverso, o acidental, o variável. Destaca-se que é "na procura da simplicidade elementar que se chega à complexidade fundamental". ${ }^{11: 28} \mathrm{~A}$ simplificação seleciona o que é de interesse do cognoscente, eliminando o que é alheio a sua finalidade, e computa o estável, o determinado e o certo. A complexificação considera o máximo de dados e informações concretas, procurando reconhecer e computar o variado, o variável, o ambíguo, o aleatório e o incerto.

Assim, da simplificação à complexificação chegamos ao conhecimento. Tanto a complexidade em si como o simples em si balançam entre o objetivo de compreender a complexidade maior possível e a reduzir esta complexidade ao menos complexo possível, com a tendência ilusória de considerar o simples em si mesmo ou o complexo em si mesmo. ${ }^{11}$

\section{A INTERDISCIPLINARIDADE E SUA APLICABILIDADE NAS AÇÕES EM SAÚ- DE E ENFERMAGEM}

Para fazer face aos pressupostos de promoção da saúde e às ameaças emergentes à saúde, há necessidade de novas ações e de construção contínua do conhecimento. O desafio para os próximos anos será ativar o potencial para a promoção da saúde inerente em muitos setores da sociedade, nas comunidades e nas famílias.

A visão habitual disciplinar, corporativa e unidimensional, que temos adotado em saúde, "tende a deformar nossa visão de mundo, o que nos leva a isolar os problemas de saúde do seu contexto, simplificando-os para tentar resolvê-los. Com isso, obtémse uma solução parcial e inadequada, dando a impressão que os problemas se repetem, quando na verdade, não foram resolvidos". ${ }^{12: 535}$

Assim, ao tratarmos mais especificamente da promoção da saúde com enfoque nas ações de Enfermagem, não podemos nos afastar da noção de interdisciplinaridade e complexidade, já que as ações envolvem mudanças, como a mudança nas comunidades, nas políticas públicas ou em comportamentos e hábitos de vida. Uma intervenção que aborda muitas dimensões da vida social pode nos apresentar muitos resultados possíveis.

As intervenções de promoção da saúde visam a melhoria da qualidade de vida e residem através do processo contínuo de complexidade, diante das suas características de diversidade e heterogeneidade. Necessitamos de uma ampla visão da base científica que 
considere a complexidade inerente à promoção da saúde num enfoque multisetorial, compartilhando com outros saberes, outras disciplinas, outros setores e com a população, com a consciência de que não há resposta fácil aos complexos fenômenos humanos.

Porém, esta "abordagem totalizadora e respeitosa da complexidade dos fenômenos da vida, saúde, doença, sofrimento e morte", que convivemos em nossa prática cotidiana em saúde, necessita "de um tratamento teórico-metodológico efetivamente transdisciplinar, tomando como base a perspectiva da complexidade". ${ }^{13: 109}$

As intervenções de saúde incluem uma mescla complexa de muitas disciplinas e campos de ação variados, com o enfoque de melhorar a saúde, reorientar os serviços de assistência e fazer com que as pessoas sejam protagonistas da sua própria saúde, exigem a compreensão que muitas disciplinas ou bases científicas podem trazer.

Ao discutir a epidemia de Aids como um problema internacional, o Ministério da Saúde enfatiza que as práticas sociais não pertencem mais a u ma comunidade nacional exclusivamente, nem os indivíduos que as realizam reconhecem apenas uma identidade distintiva e homogênea, como antes era pensado. "A diversidade opera tanto nas formas diferentes de se perceber a realidade e, em última instância, de se viver, quanto nas formas desiguais em que as pessoas e os grupos sociais incorporam novos valores, atitudes e práticas através dos fluxos interculturais". ${ }^{14: 136}$ Neste sentido, a noção de território é porosa e susceptível de mediar com múltiplos cenários, transcendendo sua original visão espacial, hoje insuficiente para a compreensão dos fenômenos que envolvem fronteiras, ora nos seus termos geopolíticos, ora na sua dimensão simbólica, ou, ainda, como no tema que nos interessa, na perspectiva das fronteiras do processo saúde-doença e na promoção da saúde.

Talvez tenhamos que considerar a saúde como produção social, como processo dinâmico e em permanente transformação, rompendo com a setorialização da realidade. Mendes reforça que este estado de saúde permite a ruptura com a idéia de um setor saúde, erigindo-a como produto social resultante de fatos econômicos, políticos, ideológicos e cognitivos. Isto significa "inscrevê-la, como campo do conhecimento, na ordem da interdisciplinaridade e, como prática social, na ordem da intersetorialidade", ${ }^{15: 241}$ o que está coerente com a nova visão de saúde como qualidade de vida e a nova visão dos sujeitos como protagonistas da sua saúde.

\section{REFLEXÕES FINAIS}

A interdisciplinaridade e a visão complexa são temas pouco discutidos na área da saúde, e mais especificamente na Enfermagem, e esta reflexão poderá nos trazer subsídios para a sua efetivação com a conseqüente melhoria da qualidade das nossas ações visando à promoção da saúde das comunidades.

Interdisciplinaridade em saúde ainda é confundida com trabalho em equipe, porém, temos clareza que sem construção de conhecimento não há interdisciplinaridade, apenas justaposição de ações parcelares, que não dão conta de atender às ameaças emergentes a saúde, de compreender as novidades das biociências, as profundas transformações da vida cotidiana e das relações de trabal ho, que desvelam o cenário complexo de um novo paradigma do conhecimento.

A atuação interdisciplinar nas equipes de saúde e Enfermagem implica em construção deste conhecimento, como aquisição de competências, uma prática de inter-relação e interação entre as diversas disciplinas, articulação dos conhecimentos, num constante ir e vir para resolução dos problemas ou alcance dos objetivos, e conseqüentemente a ampliação das fronteiras disciplinares. Implica em reflexão-ação-reflexão. Esse constante construir, desconstruir e reconstruir pode contribuir para a evolução e inovação da Enfermagem como conhecimento e profissão.

O esforço é essencial no sentido de que se estabeleça uma nova visão frente aos problemas que afetam a saúde, com enfoque da promoção da saúde em nossa sociedade, apontando para a construção de novos saberes através da interação entre os campos disciplinares, com sujeitos construindo com sua experiência de vida novos saberes científicos.

Mesmo diante das transformações que temos observado em nossa sociedade, em tempos de mudanças paradigmáticas e estruturais, os serviços de saúde continuam equivocadamente assumindo a responsabilidade pela condução do viver saudável em sociedade. Ao superar esta noção de saúde como atribuição exclusiva do setor saúde, partimos para uma ação intersetorial que destaca a saúde no contexto das políticas sociais e de participação da população no processo das decisões e controle das condições de saúde do indivíduo e da coletividade.

Vivemos numa sociedade plural. A diversidade, ou seja, uma justaposição de pessoas, culturas, tradições, diferenças políticas, históricas, religiosas e de estilos de vida caracterizam a sociedade atual. As distân- 
cias foram encurtadas com o intenso movimento migratório e surgem maiores diferenças entre pessoas que vivem lado a lado. Esta sociedade é produzida e produtora de sujeitos, profissionais de saúde ou clientes, que interagem e objetivam melhores condições de saúde e vida.

Assim, temos o desafio da pluralidade em nossa vida e prática profissional. A sociedade é um todo e devemos pensar este desafio com o esforço de ampliar o nosso entendimento a respeito da interação das partes rumo à unidade e totalidade nesta diversidade, de forma que os diversos setores da sociedade percebam-se interdependentes e responsáveis na construção de uma sociedade mais solidária e saudável. Esta nova visão a interdisciplinaridade e a complexidade nos trazem.

\section{REFERÊNCIAS}

1 Nunes ED. A questão da interdisciplinaridade no estudo da saúde coletiva e o papel das ciências sociais. In: Canesqui AM, organizadora. Dilemas e desafios das ciências sociais na saúde coletiva. São Paulo-Rio de Janeiro: HucitecAbrasco; 1995. p. 95-115.

2 Morin E. A religação dos saberes: o desafio do século XXI. Rio de Janeiro: Bertrand Brasil; 2001.

3 Japiassu H. Interdisciplinaridade e patologia do saber. Rio de Janeiro: Imago; 1976.

4 Morin E. Educação e complexidade: os sete saberes e outros ensaios. São Paulo: Cortez; 2002.
5. Etges NJ. Ciência, Interdisciplinaridade e Educação. In: Jantsch AP, Bianchetti L. Interdisciplinaridade: para além da filosofia do sujeito. Petrópolis: Vozes, 1995. p. 51-84.

6 DemoP. Metodologia doconhecimentocientífico. São Paulo: Atlas; 2000.

7 Morin E. O Método 5: a humanidade da humanidade. Trad. Juremir Machado da Silva. Porto Alegre: Sulina, 2002.

8 Cury CRJ.Educaçãoe contradição: elementos metodológicos para uma teoria crítica do fenômeno educativo. 6a. ed. São Paulo: Cortez; 1995.

9 Morin E. A cabeça bem-feita: repensare reforma, reformar o pensamento. Rio de Janeiro: Bertrand; 2000.

10 Santos BS. A crítica da razão indolente: contra o desperdício da experiência. 3a. ed. São Paulo: Cortez; 2001.

11 Erdmann AL. Sistema de cuidados de enfermagem. Pelotas: Universitária/UFPEl; 1996.

12 Koerich MS, Erdmann AL. Enfermagem e patologia geral: resgate e reconstrução de conhecimentos para uma prática interdisciplinar. Texto e Contexto. 2003 Out.-Dez; 12 (4): 528-37.

13 Almeida Filho N, Andrade RFS. Holopatogênese: esboço de uma teoria geral de saúde-doença como base para a promoção da saúde. In: Czeresnia D, Freitas CM. Promoção da saúde: conceitos, reflexões, tendencias. Rio de Janeiro: Fiocruz; 2003; p.97-116.

14 Ministério da Saúde (BR). Secretaria de Políticas de Saúde. A resposta brasileira ao HIV/Aids: experiências exemplares. Brasília: Coordenação Nacional de DST/Aids; 1999.

15 Mendes EV. Uma agenda para a saúde. São Paulo: Hucitec; 1996. 